\title{
The influence of natural clay and organoclay vermiculite on the formation process of bionanocomposites with poly (3-hydroxybutyrate-co-3-hydroxyvalerate)
}

\author{
Dilson Cristino da Costa Reis ${ }^{1}$, Thainá Araújo de Oliveira ${ }^{2}$, \\ Laura Hecker de Carvalho ${ }^{3}$, Tatianny Soares Alves ${ }^{1,4}$, \\ Renata Barbosa ${ }^{1,4}$
}

\footnotetext{
${ }^{1}$ Federal University of Piauí - UFPI, Graduate Program in Materials Science, Research Group and Polymer Conjugates Materials, Teresina, PI, Brazil, CEP 64049-550.

${ }^{2}$ Federal University of Piauí - UFPI, Chemistry Department, Research Group and Polymer Conjugates Materials, Teresina, PI, Brazil, CEP 64049-550.

${ }^{3}$ Federal University of Campina Grande - UFCG, Center Science and Technology - Graduate Program in Materials Science and Engineering. Campina Grande, PB - Brazil.

${ }^{4}$ Federal University of Piauí - UFPI, Technology Center, Department of Materials Engineering - Av. Ininga, S/N - Teresina, Piauí, Brazil, CEP 64049-550. e-mail: rrenatabarbosa@yahoo.com
}

\begin{abstract}
During the last decades, a lot of research work focused on several biodegradable and biosourced polyesters for the purpose of reducing the non-degradable polymer wastes. These polyesters are particularly considered to be promising polymers for biomedical applications and short life-time products like packaging. As these packagings are rapidly discarded, especially the food ones, their accumulation becomes a serious environmental problem. In order to replace these materials with new ones that do not harm the environment, several studies are being carried out about these materials. However, it presents some limitations as its thermal instability in the molten state and high cost of production, being the incorporation of clay to the polymer matrix, forming bionanocomposites, a viable alternative since it improves the mechanical and thermal properties of the material when compared to the pure polymer, and may or may not reduce the total cost of production. Among commercially-available polyesters, polyhydroxyalkanoates (PHAs) are produced by various bacteria and known to be fully biodegradable. The aim of this study was to develop and to characterize bionanocomposites produced from the polymer matrix of poly (3-hydroxybutyrate-co-3-hydroxyvalerate) - PHBV and natural vermiculite and organoclay. The melt intercalation technique was used for obtaining systems in the form of films. The FTIR results unveiled changes in the bionanocomposites structure with the addition of the clay, verifying the incorporation and overlap of bands of both the natural clay and the quaternary ammonium salt. Through the XRD technique, it was observed a greater disorganization in the systems compared to the pure polymer, suggesting a structure of a microcomposite for the systems with natural clay and tending to a greater exfoliation for the systems with organoclay vermiculite. From the micrographs by MO and MEV, the films presented a small number of clusters for the natural systems and a more uniform structure for the organophilic systems, thus corroborating with the XRD. In this way, it was evidenced that the systems with organoclay were the ones that presented better against the characteristics desired for its possible industrial application. Thus, elaborated bionanocomposites may be an alternative to the substitution of synthetic polymers in the industry, for example, in food packaging.
\end{abstract}

Keywords: bionanocomposites, polymeric composites, polymers, FTIR and X-ray technique.

\section{INTRODUCTION}

The high durability of polymers is due to their resistance to chemical and biological attacks which causes a great impact on the environment on account of the fact that waste is produced without proper destination that last for hundreds of years. Therefore, the study of biodegradable polymers has been widespread because they have high rates of degradation and generate less environmental impact [1].

One of biodegradable polymers showing a growing industrial interest is the poly (3-hydroxybutyrateco-3-hydroxyvalerate) - PHBV, a PHB copolymer synthesized by bacteria from agricultural raw materials having good biodegradability, biocompatibility and thermoplasticity [2]. However, it presents some limita- 
tions on its use on a large scale due to its thermal instability in the molten state and high cost of production [3]. Alternatively, the clay incorporation to the polymeric matrix can occur, forming nanocomposites or bionanocomposites, improving the mechanical and thermal properties of the material compared to pure polymer [4].

For PHBV based nanocomposites, the use of organomodified nanoclays containing a surfactant appears to be asuitable way to improve the affinity between nanoclays and the polymer and the dispersion of nanoclays in the matrix [5, 6]. Concerning the transport properties of PHBV-based nanocomposites, SanchezGarcia and Lagaron [7] showed for PHBV/mica (5wt\%) nanocomposites a decrease in water vapor and oxygen permeability of $50 \%$ and $25 \%$, respectively. Recently, for PHBV/Cloisite ${ }^{\circledR} 30 \mathrm{~B}$ nanocomposites, Corrêa et al. [8] observed a reduction in oxygen permeability reaching $12 \%$ explained by tortuosity effects. However, in addition to tortuosity effects, other factors have to be taken in to account to better understand the transport mechanisms of small molecules, like the dispersion state of nanoclay platelets, the increase of crystallinity caused by nucleation effects of nanoclays, the change in molecular weight of the polymer matrix, the nanoclay content, the properties of matrix/ nanoclays interfacial zones and the interactions between the diffusing species and the components of the nanocomposite [9-11].

Therefore, this study aimed at the development and characterization of bio-nanocomposites from the polymer matrix PHBV clay and natural and organoclay vermiculite. Bionanocomposites in the form of films were prepared by melt intercalation technique and was evaluated the effect of clay evaluated through Fourier Transform Infrared Spectroscopy (FTIR), X-ray Diffraction (XRD), Scanning Electron Microscopy (SEM) and Optical Microscopy (OM). All of this with the main purpose of applying these materials as food packaging.

\section{MATERIALS AND METHODS}

\subsection{Materials}

The PHBV employed was supplied by PHB Industrial S/A (Sao Paulo, Brazil) as powder. The expanded vermiculite clay (VMT) used was provided by Mineração Pedra Lavrada - Paraíba. The organophilization of VMT was carried out with the salt chloride of stearyl dimethyl ammonium, known commercially as Praepagen $\mathrm{WB}^{\circledR}$.

\subsection{Methods}

\subsubsection{Organophilization and processing of bionanocomposites (melt intercalation)}

The organophilization process consists in the preparation of dispersions containing distilled water concentrations, the clay, and ammonium salt, as proposed by Mesquita et al. methods [12].

The bio-nanocomposites were prepared in a HAAKE internal mixer, Rheomix 3000 model, with chamber featuring a free volume of $310 \mathrm{~cm}^{3}$ and rotors of the "roller" type. A $70 \%$ fill factor of the mixing chamber was used in all cases and the mixer was operated at $170{ }^{\circ} \mathrm{C}$ at $50 \mathrm{rpm}$ for 10 minutes. The concentrations of clay without treatment and organoclay used were $1 \%, 3 \%$ and $6 \%$.

The concentrates were ground and then compression molded in a $\mathrm{MH}-08-\mathrm{MN}$ hydraulic press from MH Equipamentos Ltda. We used the temperature level of $190{ }^{\circ} \mathrm{C}$ and applied a force of 2 tons for 3 minutes. The materials obtained in the form of films were allowed to cool to room temperature. The composition and symbology used for bionanocomposites are shown in Table 1.

Table 1: Composition and symbology used for bionanocomposites PHBV and vermiculite

\begin{tabular}{c|c|c}
\hline PHBV & NATURAL VERMICULITE & SYMBOLOGY \\
\hline $100 \%$ & $0 \%$ & PHBV pure \\
\hline $0 \%$ & $100 \%$ & VMT \\
\hline $99 \%$ & $1 \%$ & PHBV + VMT 1 $\%$ \\
\hline $97 \%$ & $3 \%$ & PHBV + VMT 3 $\%$ \\
\hline $94 \%$ & $6 \%$ & PHBV + VMT 6 $\%$ \\
\hline PHBV & ORGANOCLAY VERMICULITE & SYMBOLOGY \\
\hline $0 \%$ & $100 \%$ & VMTO \\
\hline $99 \%$ & $1 \%$ & PHBV + VMTO 1 $\%$ \\
\hline $97 \%$ & $3 \%$ & PHBV + VMTO 3 $\%$ \\
\hline $94 \%$ & $6 \%$ & PHBV + VMTO 6 $\%$ \\
\hline
\end{tabular}




\subsubsection{Characterization}

The spectral analysis in Fourier Transform Infrared Spectroscopy (FTIR) was performed on a Shimadzu IRAffinity-1 model, sweeping spectrometer $4000-450 \mathrm{~cm}^{-1}$.

The nanocomposites were analyzed by the X-ray diffraction (XRD) method in a Shimadzu model

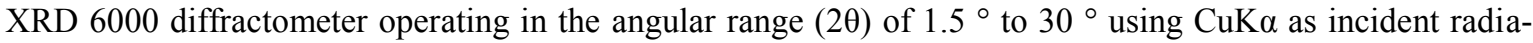
tion and $\lambda=1.54 \AA$.

The surface morphology of the systems was examined by a Shimadzu scanning electron microscope, SSX-550 model, and with a magnitude of $500 \mathrm{x}$ and also by optical microscopy with an increase of $20 \mathrm{X}$ $(200 \mu \mathrm{m})$ using a Leica Microsystems optical microscope, M750 model.

\section{RESULTS AND DISCUSSION}

\subsection{Changes in the chemical structure of the bio-nanocomposite by FTIR}

Figure 1 shows the spectrum of the bionanocomposites produced from natural vermiculite. The bands observed for pure PHBV were in $3439 \mathrm{~cm}^{-1}$ representing OH stretching vibration. Other PHBV bands are at $2933 \mathrm{~cm}^{-1}$ and $2981 \mathrm{~cm}^{-1}$, representing the vibrational stretch of aliphatic C-H groups and the asymmetrical stretching of $\mathrm{CH}_{3}$, respectively. The bands in the region of $1747-1699 \mathrm{~cm}^{-1}$ refers to stretching vibration of $\mathrm{C}=\mathrm{O}$ of the ester group present in the polymer. Symmetric and asymmetric deformation of the $\mathrm{CH}_{3}$ and the vibrational stretching C-O-C are represented the transmittance bands observed in $1452 \mathrm{~cm}^{-1}$ and in the region $1296-1114 \mathrm{~cm}^{-1}$. The other bands observed between $1000-500 \mathrm{~cm}^{-1}$ are related to stretches of C-C group. Thus, the spectrum of pure PHBV has some characteristic bands previously reported in the study by Liu et al. [13] Weng et al. [14].

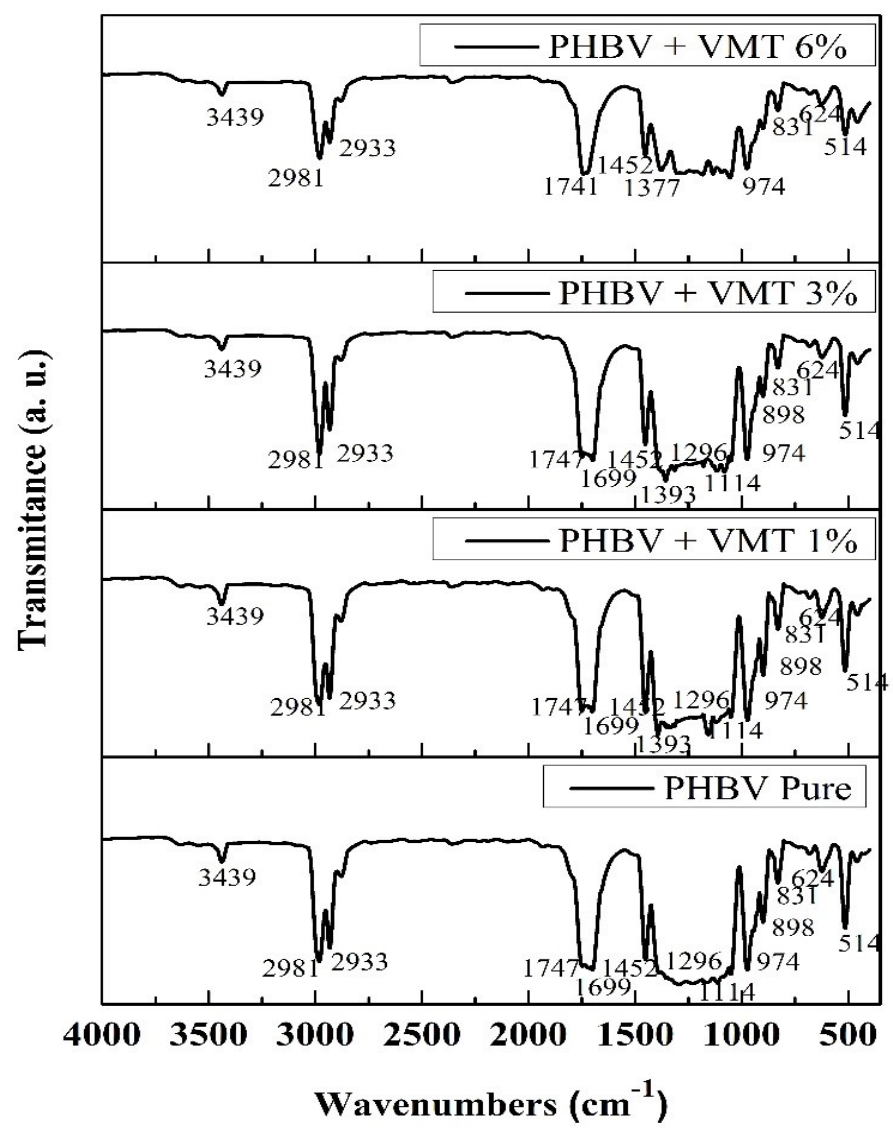

Figure 1: Spectra of infrared (FTIR) of pure PHB and bionanocomposites produced with natural vermiculite. 
Note that with the increasing of the clay content in the bionanocomposites, the bands remain in the same wavelength, which suggests that the chemical structure of bionanocomposites was not significantly altered by the insertion of natural clay. The decrease of $\mathrm{C}-\mathrm{H}$ methylenes groups is observed, resulting in a disorder of the functional groups, characteristic of the polymer, similar results were found by Silva et al [15]. In its study on the organomodification effects of vermiculite clay and its potential for the production of poly (lactic acid) bionanocomposites (PLA) and organoclay vermiculite, Fernández et al. [16] reported bands found in natural vermiculite, one in $3640 \mathrm{~cm}^{-1}$ related to stretch-vibration $\mathrm{O}-\mathrm{H}$ possibly of hydration water and bound silane groups. Another characteristic band of clay is in the region of $1650 \mathrm{~cm}^{-1}$ due to hydration water $\mathrm{OH}$ flexion vibrations and strong bands were also found in the region of $1000-450 \mathrm{~cm}^{-1}$, attributed to $\mathrm{Si}-\mathrm{O}-\mathrm{Si}$ and Si-O-Al. The characteristic bands of natural vermiculite are not easily observed in PHBV / vermiculite bionanocomposites developed due to possible overlap of the bands of the pure polymer. This overlap was also demonstrated by Yang et al. [17].

Figure 2 illustrates the infrared spectra for bionanocomposites produced from organoclay vermiculite. The relative bands on the pure PHBV are also observed in organophilic systems, however with a greater intensity difference compared to systems with natural clay. Observed an increase in the $3439 \mathrm{~cm}^{-1}$ band, possibly attributed to stretching vibration of $\mathrm{N}-\mathrm{H}$, representing the presence of the quaternary ammonium salt in the modified clay and thus on the bionanocomposites. As reported by Wang et al. [18] in the paper where polystyrene and vermiculite nanocomposites were developed by in situ polymerization technique.

The Figure 2 also noticed a slight increase in other bands reported for PHBV, as the region 3000 - 900 $\mathrm{cm}^{-1}$ bands of ammonium quaternary salt are overlapping the bands of the polymer. Oliveira et al. [19] observed the appearance of bands 2960 and $2857 \mathrm{~cm}^{-1}$ attributable to C-H stretching when they modified the clay vermiculite, which can explain the increase in the band $2920 \mathrm{~cm}^{-1}$ in these systems. We also observed new bands at 2922 and $2847 \mathrm{~cm}^{-1}$ related to organophilization of vermiculite, supported by Gomes et al. [20].

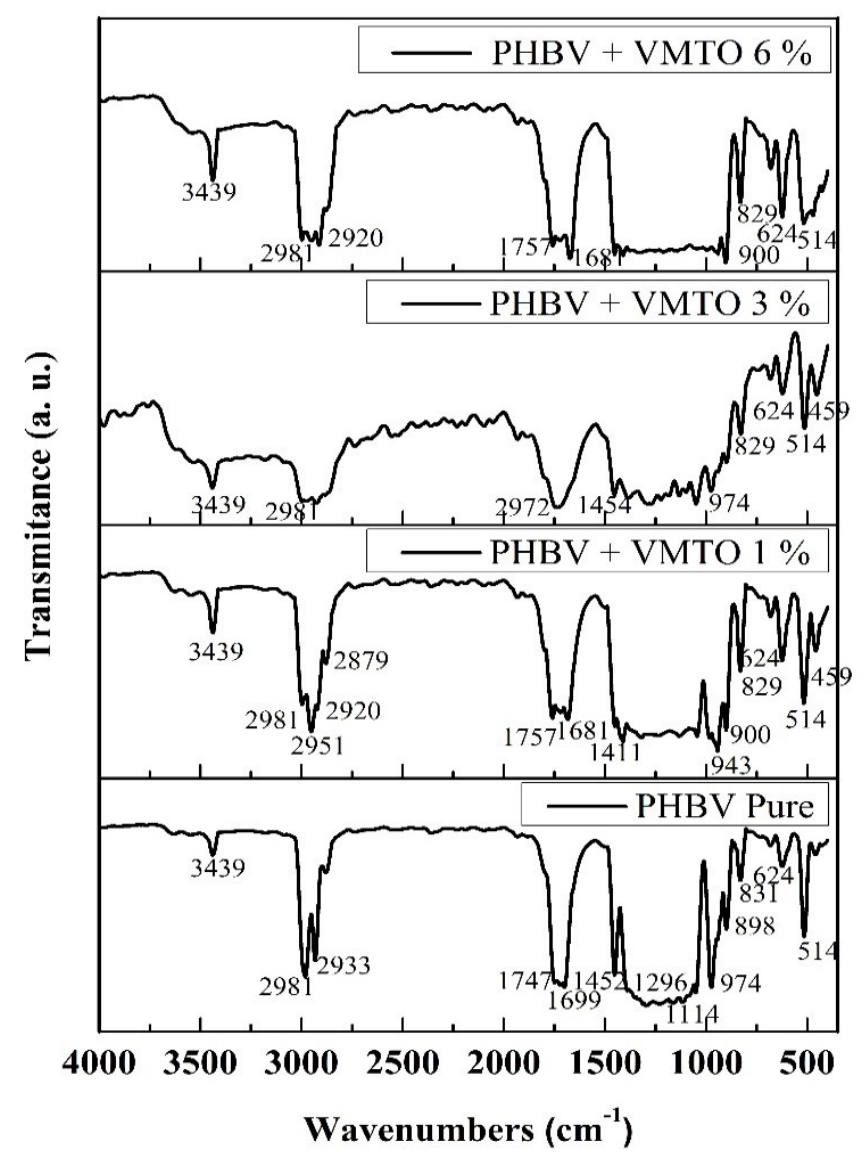

Figure 2: Spectra of infrared (FTIR) of pure PHB and bionanocomposites produced with organoclay vermiculite. 


\subsection{Crystalline structure}

Figure 3 presents the XRD analysis of natural clay, pure PHBV and of bionanocomposites produced with natural vermiculite. For natural vermiculite clay, three characteristic peaks at $2 \theta$ equal to $3.96^{\circ} ; 6.28^{\circ}$ and $7.18^{\circ}$, with interlayer spacings of $23.92 \AA ; 14.06 \AA$ and $12.30 \AA$, were respectively observed. This result corroborates the one found in the diffractograms of natural vermiculite conducted by Zhang et al. [21] and Fernandez et al. [16].

It was noticed that the first clay vermiculite peak does not appear in the three established bionanocomposites and the other two characteristic clay peaks present larger basal spacing in the systems, passing from distance $\mathrm{d} 001=14.06 \AA$ of the vermiculite clay to 14.42 in the system with $1 \%$ clay and $14.19 \AA$ for the systems with 3 to $6 \%$ of nanofiller. Thus, with increasing clay content in the bionanocomposites there occurs an increase in peak intensity, which is possibly due to the presence of a minimum of intercalation of polymer chains between the layers of vermiculite. One can notice the formation of a possible structure of a microcomposite in the bionanocomposites according to Crétois et al. [22]. However, it can also be observed that as the vermiculite content increases in the systems, so does the intensity of the peaks related to clay, possibly indicating that the number and size of the agglomerates slightly increased, as has also been reported in the literature by Yang et al. [17].

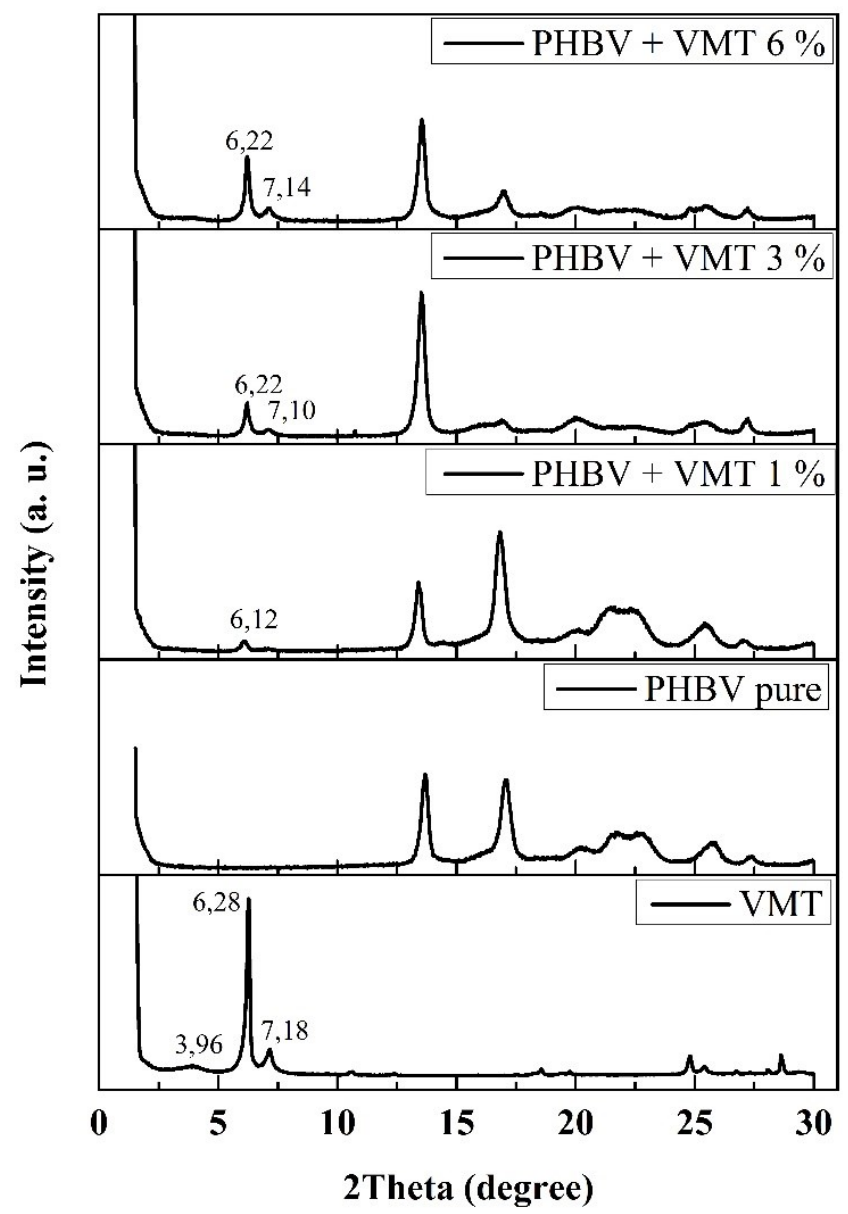

Figure 3: X-ray diffraction of the bionanocomposites with natural vermiculite.

Figure 4 illustrates the diffactrograms for modified vermiculite, pure PHBV and their bionanocomposites produced with organoclay vermiculite. From the XRD pattern of the organoclay vermiculite, four different peaks can be seen compared to the natural vermiculite, they were at $2 \theta=1.94^{\circ} ; 2.34^{\circ} ; 4.74^{\circ}$ and $7.06^{\circ}$, corresponding to $45.48 \AA$ basal spacing; $37.71 \AA ; 18.62 \AA$ and $12.51 \AA$, respectively. These distances were further apart for organoclay vermiculite compared to what it is like in its natural way. Thus, the increase in 
basal spacing suggests that the alkylammonium cations have been well intercalated between layers of silicate, corroborating the results obtained by Fernandez et al. [16], when evaluating the organomodification of the vermiculite for the production of PLA / vermiculite nanocomposites, also found two similar peaks for the natural clay, being $7.34^{\circ}(12.0 \AA)$ and $3.50^{\circ}(25.2 \AA)$, both Corresponding to baseline interplanar distance $\mathrm{d}_{001}$, and Gomes et al. [20] observed similar peaks for the natural vermiculite clay prior to their organophilization and observed that the intercalation of the quaternary ammonium salt in the vermiculite clay is due to the greater distance of the silicate galleries.

It may be noted that in the systems with 1 and $3 \%$ organoclay, no clay peak can be observed, and only the intensity of the peaks relating to pure PHBV go through change and there is also a slight increase in their basal spacing. For the system with $6 \%$ organoclay vermiculite, the presence of a diffraction peak related to organoclay vermiculite with an increase in the basal spacing was observed, which characterizes a larger intercalation of polymer chains in the clay lamellae. Thus, the higher the clay content added to the systems, the more one can observe a change in structure which possibly goes from exfoliated to intercalated, similar to the study by Cretois et al. [22] and Carli et al. [23].

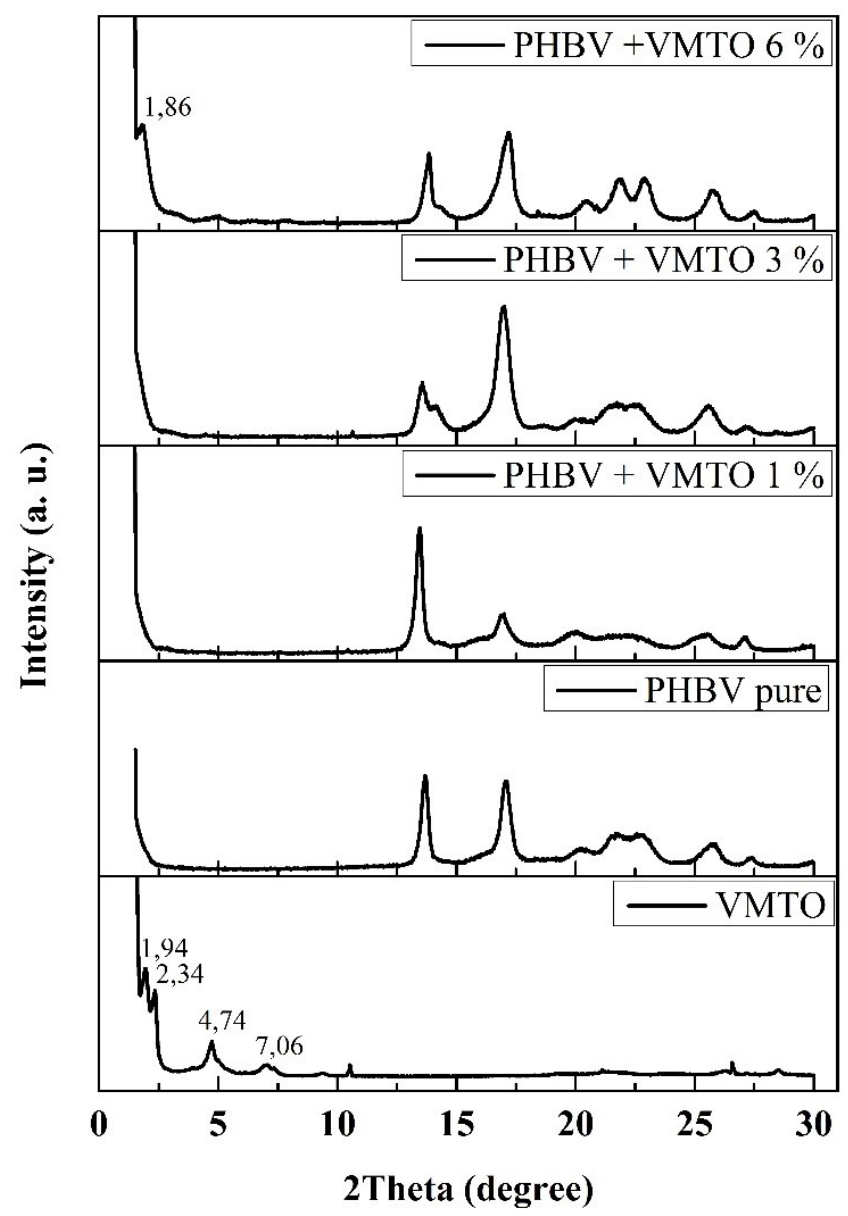

Figure 4: X-ray diffraction of the bionanocomposites with organoclay vermiculite

\subsection{Morphology of bionanocomposites}

Figure 5 illustrates the optical micrographs (MO) and scanning electron microscopy (SEM) for pure PHBV and for the bionanocomposites. Through the micrographs, it was observed that the PHBV polymer presented uniform morphology and no grooves. A number of denser points have also been observed, possibly characterizing incomplete melting or the presence of impurities. For systems with natural clay, was observed the formation of small white pellets in more detail, possibly from the clay not completely dispersed in the polymer, and even more notoriously with the highest percentage of nanoclay. Thire et al. [24] also observed the 
formation of white spots in the PHBV / attapulgite systems. Note that the bionanocomposites with organoclay were found to be more homogeneous and dispersed than the others, because the presence of clay is hardly seen. This may be due to a greater interaction between the organoclay vermiculite and the polymer matrix of PHBV, which was confirmed by XRD technique which showed a possible tendency to the exfoliation of the structures of organophilic systems due to non-appearance of the characteristic peaks of vermiculite in these bionanocomposites. Systems without stains and white spots were noticed by Oliveira et al. [19] as they developed bionanocomposites of Ecobrás ${ }^{\circledR}$ and vermiculite, which obtained very homogeneous SEM micrographs for bionanocomposites, confirmed by the good dispersion of clay.
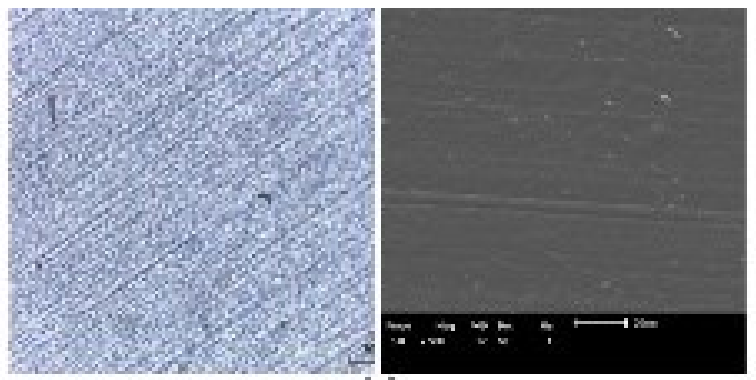

(a)
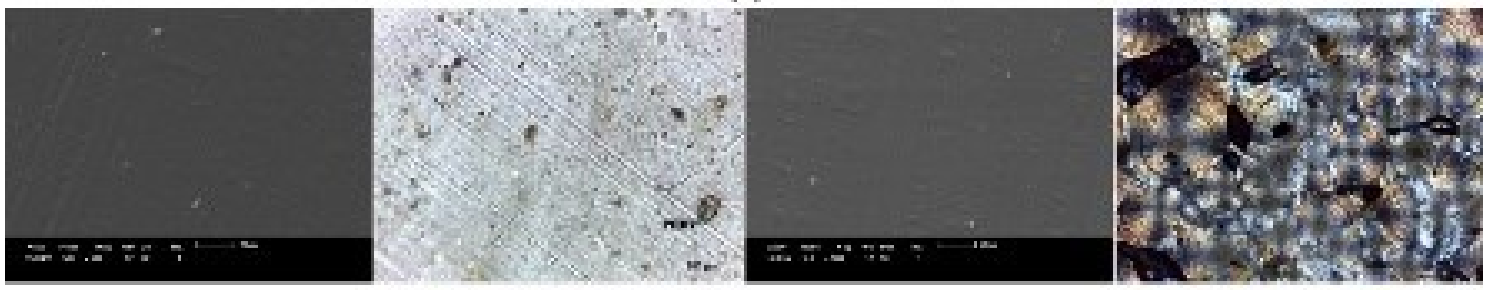

(b)

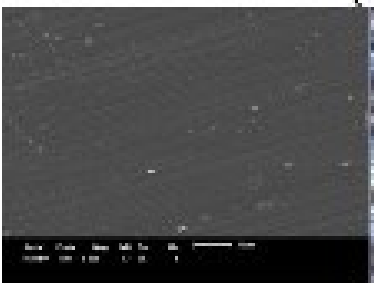

(c)
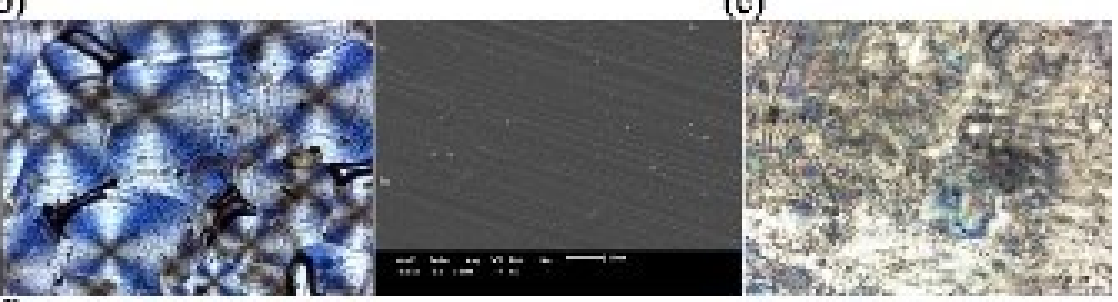

(d)

(e)

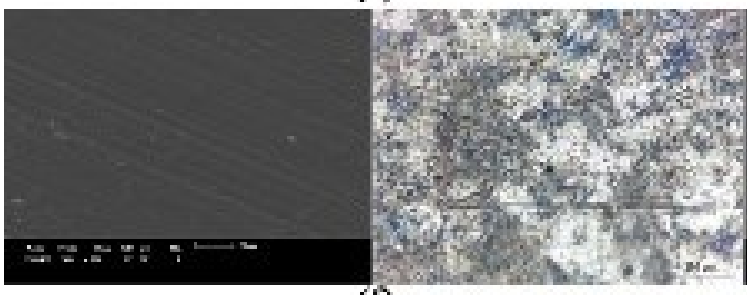

(f)

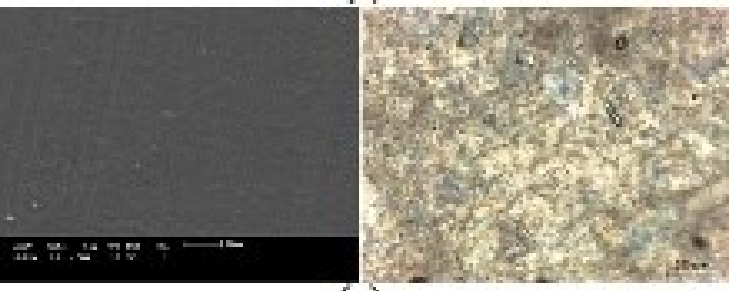

(g)

Figure 5: Optical micrographs (20X) and SEM (500X) for PHBV pure and for bionanocomposites: a) PHBV pure; b) PHBV + VMT $1 \%$; c) PHBV + VMT $3 \%$;) PHBV + VMT $6 \%$; e) PHBV + VMTO $1 \%$; f) PHBV + VMTO $3 \%$; g) PHBV + VMTO $6 \%$

\section{CONCLUSIONS}

The prepared bionanocomposites showed a disruption in the system compared to the pure polymer, observed by XRD and FTIR techniques, suggesting a structure of a microcomposite for systems with natural clay and a possible exfoliation for systems with organoclay vermiculite. From the results of SEM and MO, it was observed that the films for natural systems showed a small amount of clay agglomerates but the systems with organoclay vermiculite had become more homogenous, which leads to a greater interaction between modified clay and the polymer. It was shown that systems with organoclay were found to be the most suitable ones considering the desired characteristics for possible industrial application, such as the replacement of synthetic polymers for food packaging. 


\section{ACKNOWLEDGEMENTS}

The authors thank the Graduate Program in Materials Science (UFPI), Laboratory of Polymer and Conjugated Materials - LAPCON/UFPI to the physical structure, CNPq and CAPES for financial support (Process: 306312/2015- 8 and 446530/2014-0).

\section{BIBLIOGRAPHY}

[1] SADI, R. K., KURUSU, R. S., FECHINE, G. J. M., DEMARQUETTE, N. R, “ Compatibilization of PP/PHB blends with ethylene copolymers: morphology and impact strength", In: 7th International Symposium on Natural Polymers and Composites, Gramado. Conference Proceedings, 2010.

[2] PRADELLA, J. G. C., Biopolímeros e intermediários químicos, Relatório Técnico n 84 396-205, São Paulo, 2006.

[3] SUDESH, K., ABE, H., DOI, Y., "Synthesis, structure and properties of polyhydroxyalkanoates: Biological polyesters", Progress Polymer Science, v. 25, pp. 1503-1555, 2000.

[4] PAN, H., CHEN, D., "Preparation and characterization of waterborne polyurethane/attapulgite nanocomposites", European Polymer Journal, v. 43, pp. 3766-3772, 2007.

[5] BORDES, P., HABLOT, E., POLLET, E., AVÉROUS, L., "Effect of clay organomodifiers on degradation of polyhydroxyalkanoates", Polymer Degradation Stability, v. 94, pp. 789-796, 2009.

[6] CARLI, L.N., CRESPO, J. S., MAULER, R .S., "PHBV nanocomposites based on organomodified montmorillonite and halloysite: the effect of clay type on the morphology and thermal and mechanical properties", Composites Part A, v. 42, pp.1601-1608, 2011.

[7] SANCHEZ-GARCIA, M. D., LAGARON, J.M.., "Novel clay-based nanobiocomposites of biopolyesters with synergistic barrier to UV light, gas, and vapour", Journal of Applied Polymer Science, v.118, pp.188$199,2010$.

[8] CORRÊA, M.C.S., BRANCIFORTI, M.C., POLLET, E., AGNELli, J.A.M., NASCENTE, P.A.P., AVÉROUS, L., "Elaboration and characterization of nano-biocomposites based on plasticized poly (hydroxybutyrate-co-hydroxyvalerate) with organomodified montmorillonite", Journal of Polymers and the Environment, v. 20, pp. 283-290, 2012.

[9] PICARD, E., VERMOGEN, A., GÉRARD, J.-F., ESPUCHE, E., "Barrier properties of nylon6- montmorillonite nanocomposite membranes prepared by melt blending: influence of the clay content and dispersion state: consequences on modelling", Journal of Membrane Science, v. 292, pp. 133-144, 2007.

[10] ALEXANDRE, B., COLASSE, L., LANGEVIN, D., MÉDÉRIC, P., AUBRY, T., CHAPPEY, C., MARAIS, S., "Transport mechanisms of small molecules through polyamide12/ montmorillonite nanocomposites", Journal of Physical Chemical B, v. 114, pp. 8827-8837, 2010.

[11] TENN, N., FOLLAIN, N., SOULESTIN, J., CRÉTOIS, R., BOURBIGOT, S., MARAIS, S., "Effect of nanoclay hydration on barrier properties of PLA/montmorillonite based nanocomposites", Journal of Physical Chemical C, v. 117, pp. 12117-12135, 2013.

[12] MESQUiTA, P. P., ARAÚJO, R. J., CARVALHO, L. H., ALVES, T. S., BARBOSA, R., “Thermal Evaluation of PHB/PP-g-MA Blends and PHB/PP-g-MA/Vermiculite Bionanocomposites after Biodegradation Test”, Polymer Engineering and Science., v. 56, p. 555- 560, 2016.

[13] LIU, Q. S., ZHU, M. F., WU, W. H., QIN, Z. Y., "Reducing the formation of six-membered ring ester during thermal degradation of biodegradable PHBV to enhance its thermal stability", Polymer Degradation Stability,v. 94, pp. 18-24, 2009.

[14] WENG, Y. X., WANG, X. L., WANG , Y. Z., "Biodegradation behavior of PHAs with different chemical structures under controlled composting conditions", Polymer Testing, v. 30, pp. 372-380, 2011.

[15] SILVA, L. C. A., THIRÉ, R. M. S., BARRETO, L. S., “Obtenção e caracterização de compósitos de PHBV/Atapulgita”, In: 10 Congresso Brasileiro de Polímeros, Foz do Iguaçu, 2009.

[16] FERNÁNDEZ, M. J., FERNÁNDEZ, M. D., ARANBURU, I., "Effect of clay surface modification and organoclay purity on microstructure and thermal properties of poly(L-lactic acid)/vermiculite nanocomposites”, Applied Clay Science, v. 80-81, pp. 372-381, 2013.

[17] YANG, C., LIU, P., GUO, J., WANG, Y. "Polypyrrole/vermiculite nanocomposites via self-assembling and in situ chemical oxidative polymerization", Synthetic Metals, v. 160, pp. 592-598, 2010. 
[18] WANG, L., WANG, X., CHEN, Z., MA, P., "Effect of doubly organo-modified vermiculite on the properties of vermiculite/polystyrene nanocomposites", Applied Clay Science, v. 75-76, pp.74-81, 2013.

[19] OLIVEIRA, M. F. L., CHINA, A. L., OLIVEIRA, M. G., LEITE, M. C. A. M., "Biocomposites based on Ecobras matrix and vermiculite”, Materials. Letters, v. 158, pp. 25-28, 2015.

[20] GOMES, E. V. D., VISCONTE, L. L. Y., PACHECO, E. B. A. V., "Processo de organofilização de vermiculita brasileira com cloreto de cetiltrimetilamônio", Cerâmica, v. 56, pp. 44-48, 2010.

[21] ZHANG, K., XU, J., WANG, K. Y., CHENG, L., WANG, J., LIU, B., "Preparation and characterization of chitosan nanocomposites with vermiculite of different modification", Polymer Degradation and Stability, v. 94, pp. 2121-2127, 2009.

[22] CRÉTOIS, R., FOLLAIN, N., DARGENT, E., SOULESTIN, J., BOURBIGOT, S., MARAIS, S., LEBRUN, L.. "Microstructure and barrier properties of PHBV/organoclays bionanocomposites ", Journal of Membrane Science, v. 467, pp. 56-66, 2014.

[23] CARLI, L. N., BIANCHI, O., MACHADO, G., CRESPO, J. S., MAULER, R. S., "Morphological and structural characterization of PHBV/organoclay nanocomposites by small angle X-ray scattering", Materials Science Engineering: C, v. 33, pp. 932-937, 2013.

[24] THIRÉ, R. M. S. M., ARRUDA, L. C., BARRETO, L. S., "Morphology and thermal properties of poly(3-hydroxybutyrate-co-3-hydroxyvalerate)/attapulgite nanocomposites", Materials Research, v. 14, pp. 340-344, 2011. 